\title{
Numerical Simulations on Droplet Coalescence in an L-shaped Duct for Inlet Fogging of Gas Turbine Engines
}

\author{
Ari Hamdani ${ }^{1}$, Motoaki Utamura ${ }^{1}$, Takanori Shibata ${ }^{2}$, Chihiro Myoren $^{2}$ \\ ${ }^{1}$ Research Laboratory for Nuclear Reactors, Tokyo Institute of Technology, Tokyo, Japan \\ 2-12-1, Ookayama, Meguro-ku, Tokyo 152-8550, Japan \\ E-mail: hamdani@us.nr.titech.ac.jp \\ ${ }^{2}$ Mitsubishi Hitachi Power Systems, Ltd.
}

\begin{abstract}
Numerical model is developed in order to characterize the water droplet coalescence at the air intake duct of a gas turbine assumed under operation of Inlet Fogging System. Water droplet size is treated as a randomly distributed parameter instead of a single size representative diameter. The numerical calculation is executed by ANSYS Fluent ${ }^{\circledR}$ v.14.5 in a simple rectangular duct and verified using experimental data. The calculated evaporation time of an isolated water droplet in an infinite room shows a good agreement with experimental data. With fogging amount below saturation condition, injected water droplets with size distributions take a longer time to evaporate and it leads to a lower cooling efficiency than the one calculated using a single representative diameter. Then, the model is used to investigate droplet coalescence phenomena in an L-shaped duct geometry. It is shown that the L-shaped duct enhances coalescence due to drift behind the corner of L-duct. This reproduces larger droplets, therefore lower evaporation efficiency and increase of the water drainage.
\end{abstract}

\section{INTRODUCTION}

In recent years, gas turbine power augmentation has drawn an attention of engineers and researchers. During the hot season, the power output and an efficiency of gas turbines are reduced significantly due to lower density air. In order to augment the power output and thermal efficiency, increasing the intake air mass flow rate is needed. The power augmentation can be achieved by air cooling technologies [1]. Among the air cooling technologies, inlet fogging technology is widely used because of its simplicity and low installation cost.

Utamura et al. [2] reported that about $1 \%$ injection of normal temperature water by spray nozzles at inlet duct had a potential to increase the power output by several percent.

Some researchers had studied this system to characterize evaporative behavior of water droplet and identified key operational parameters [3]. Chaker et al [4] and Jeanty F., et al [5] investigated, experimentally and numerically, the synchronization distance of droplets in continuous phase. They found that injected droplet velocity attains the airflow velocity in a few milliseconds due to the large drag forces. As droplet Reynolds number is very small, the coefficient of drag is exceedingly large and the droplet accelerates very rapidly. Therefore, the slip velocity between injected droplet and air flow becomes quickly zero i.e. synchronization distance is of the order of $0.1 \mathrm{~m}$. Computational

Manuscript Received on July 18, 2014

Review Completed on June 23, 2015
Fluid Dynamic (CFD) was used to predict flow behavior for different condition and configurations. Suryan A., et al [6] numerically investigated the suitable locations for spray nozzles within the air intake duct. However, those studies were executed using a single representative diameter, typically the Sauter Mean Diameter (D32) and droplet coalescence effect was not considered.

In this paper, both droplet size distributions and coalescence effect were investigated numerically in an L-shape duct. Validating the present method with experiment, the present study investigated the effect of distributed droplet size on evaporation efficiency and introduced the effect of droplets coalescence phenomenon in duct geometry.

$\begin{array}{cl}\text { NOMENCLATURE } \\ a & \text { constant [-] } \\ b & \text { constant [-] } \\ B C & \text { boundary condition [-] } \\ C p & \text { isobaric specific heat }[\mathrm{J} / \mathrm{kg} / \mathrm{K}] \\ C V & \text { control volume } \\ D_{d} & \text { droplet diameter [ } \mu \mathrm{m}] \\ D 32 & \text { Sauter Mean Diameter }[\mu \mathrm{m}] \\ D_{f} & \text { diffusion coefficient of water vapor }\left[\mathrm{m}^{2} / \mathrm{s}\right] \\ f & \text { complex function } \\ I & \text { evaporation rate }[\mathrm{kg} / \mathrm{s}] \\ L & \text { latent heat }[\mathrm{J} / \mathrm{kg}] \\ L e & \text { length [m] } \\ m & \text { mass [kg] } \\ N_{A B} & \text { number of collisions between parcels [-] } \\ n & \text { number of droplets in parcel }[-] \\ N u & \text { Nusselt number [-] } \\ P r & \text { Prandtl number [-] } \\ P(\kappa) & \text { probability as function of } \kappa[-] \\ Q & \text { heat transferred from air to droplet }[\mathrm{W}] \\ R e & \text { Reynolds number [-] } \\ R H & \text { relative humidity [\%] } \\ r & \text { radius of droplet [m] } \\ S c & \text { Schmidt number [-] } \\ S h & \text { Sherwood number [-] } \\ T & \text { temperature }\left[\mathrm{K},{ }^{\circ} \mathrm{C}\right] \\ T_{d} & \text { droplet temperature }\left[\mathrm{K},{ }^{\circ} \mathrm{C}\right] \\ T_{a} & \text { ambient air temperature }\left[\mathrm{K},{ }^{\circ} \mathrm{C}\right] \\ T_{\infty} & \text { air temperature at infinity }\left[\mathrm{K},{ }^{\circ} \mathrm{C}\right] \\ T_{a} & \text { humid air temperature }\left[\mathrm{K},{ }^{\circ} \mathrm{C}\right] \\ t & \text { time [s] } \\ \Delta t & \text { time step [s] } \\ U_{r e l} & \text { relative velocity of droplet A to B[m/s] } \\ u & \text { air velocity [m/s] } \\ u_{d} & \text { droplet velocity [m/s] } \\ & \end{array}$

Copyright $(2015$ Gas Turbine Society of Japan 


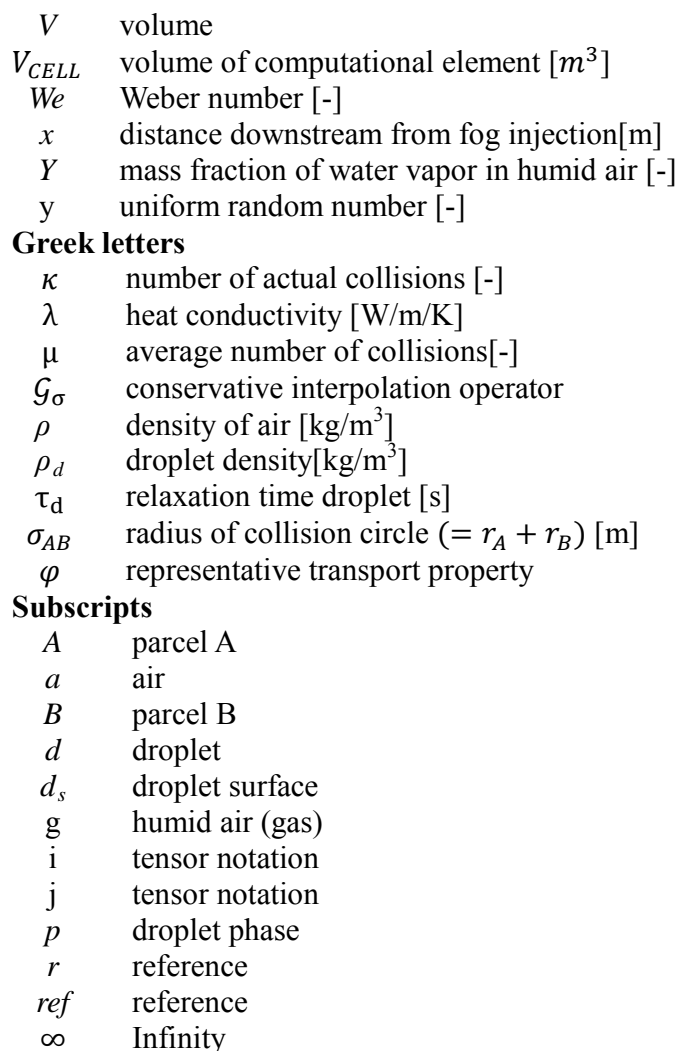

\section{INLET FOGGING SYSTEM}

The power output of gas turbines depends on the density of the intake air. During summer, hot weather decreases air density, that means that less mass of air flows into a gas turbine and the power decreases. Because of this, many inlet cooling technologies such as inlet fogging system are installed in order to get cooler air. This technology has been widely applied in real gas turbine engines because of its low capital cost, low maintenance requirements, and quick installation. The other advantages of inlet fogging system are negligible pressure drop across the nozzle and possible $30 \%$ reduction of NOx gas emissions produced in the combustor.

However, inlet fogging system has some disadvantages. The disadvantages include the need for demineralized water and the fact that power augmentation is limited by the ambient wet bulb temperature (on rainy days very small cooling will be obtained). The other disadvantage is the inlet fogging cannot be used when the ambient wet bulb temperature is less than $10{ }^{\circ} \mathrm{C}$, thus inlet fogging must be shut down in order to prevent frost formation at the compressor inlet. Nevertheless, inlet fogging system has positive experiences among the other cooling technologies.

The concept of gas turbine inlet fogging system is shown in Fig.1. Water fog is generated by spray nozzles upstream the inlet duct and it is mixed with the incoming ambient air. Fine water droplets with typical Sauter mean diameter of $20 \mu \mathrm{m}$ rapidly reach airflow velocity due to drag force. Droplets evaporate and can cool the air down to as much as wet bulb temperature, for which the air becomes saturated. A part of unevaporated water may attach to duct wall and be drained, the rest enters the compressor. Thus, design of inlet fogging system attempts to minimize the loss of water due to the drain while attaining highest cooling efficiency.

In this paper, both droplet size distributions and coalescence effect were investigated numerically in an L-shape duct. As shown in Fig.1, the droplet coalescence will be analyzed on the corner of inlet duct just before the compressor.

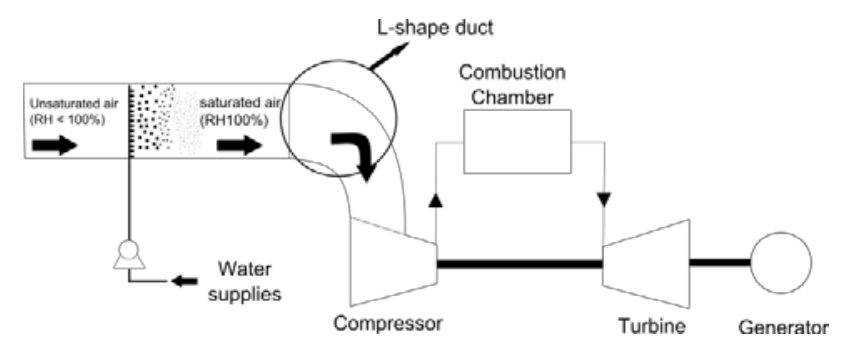

Fig.1 Concept of Inlet Fogging for a gas turbine.

\section{THE NUMERICAL MODEL}

Gas-Phase Equations

The three-dimensional, incompressible, filtered Navier-Stokes equations are solved on a structured grid with arbitrary elements. These equations are written as

$$
\frac{\partial \overline{u_{i}}}{\partial t}+\frac{\partial \bar{u}_{1} \bar{u}_{j}}{\partial x_{j}}=-\frac{\partial \emptyset}{\partial x_{i}}+\frac{1}{\operatorname{Re}_{\text {ref }}} \frac{\partial^{2} \overline{u_{i}}}{\partial x_{j} x_{j}}-\frac{\partial q_{i j}}{\partial x_{j}}+\overline{\dot{S}_{1}}
$$

where $\mathrm{q}_{\mathrm{ij}}$ denotes the anisotropic part of the subgrid-scale stress tensor, $\overline{u_{1}} \bar{u}_{j}-{\overline{u_{1}}}_{\bar{j}}$, and the overbar indicates filtered variables. Equation (1) is non-dimensionalized by the reference length, velocity, and density scales, $L e_{r e f}, U_{\text {ref }}, \rho_{\text {ref }}$, respectively. The reference Reynolds number is defined as $R e_{r e f}=\rho_{\text {ref }} L e_{r e f} U_{r e f}$ $/ \mu_{\text {ref }}$. The source term $\bar{S}_{1}$ in the momentum-equations represent the "two-way" coupling between the gas and particle-phases and is given by

$$
\overline{\dot{S}_{1}}=-\sum_{\mathrm{k}} \mathcal{G}_{\sigma}\left(\mathrm{x}, \mathrm{x}_{\mathrm{p}}\right) \frac{\rho_{\mathrm{p}}^{\mathrm{k}}}{\rho_{\mathrm{ref}}} \mathrm{V}_{\mathrm{p}}^{\mathrm{k}} \frac{\mathrm{du} \mathrm{pi}^{\mathrm{k}}}{\mathrm{dt}}
$$

where the subscript $\mathrm{p}$ stands for the droplet phase. The summation $\sum \mathrm{k}$ is over all droplets in a computational control volume. The function $\mathcal{G}_{\sigma}$ is a conservative interpolation operator with the constraint $\int \mathrm{V}_{\mathrm{cv}} \mathcal{G}_{\sigma}\left(\mathrm{x}, \mathrm{x}_{\mathrm{p}}\right) \mathrm{dV}=1$, where $\mathrm{V}_{\mathrm{cv}}$ is the volume of the grid cell and $V_{p}^{k}$ is the volume of the $k^{\text {th }}$ droplet.

\section{Liquid-phase Equations}

Droplet dynamics is simulated using a Lagrangian pointparticle model. It is assumed that (1) the density of the droplets is much greater than that of the carrier fluid, (2) the droplets are dispersed, (3) droplet deformation effects are small and (4) motion due to shear is negligible. Under these assumptions, the Lagrangian equations governing the droplet motions become

$$
\frac{\mathrm{dx}_{\mathrm{d}}}{\mathrm{dt}}=\mathrm{u}_{\mathrm{d}} ; \frac{\mathrm{du}_{\mathrm{d}}}{\mathrm{dt}}=\frac{1}{\tau_{\mathrm{d}}}\left(\mathrm{u}_{\mathrm{g}, \mathrm{d}}-\mathrm{u}_{\mathrm{d}}\right)+\left(1-\frac{\rho_{\mathrm{g}}}{\rho_{\mathrm{d}}}\right) \mathrm{g}
$$

where $x_{d}$ is the position of the droplet centroid, $u_{d}$ denotes the droplet velocity, $u_{g, d}$ the gas-phase velocities interpolated to the droplet location, $\rho_{\mathrm{d}}$ and $\rho_{\mathrm{g}}$ are the droplet and gas-phase densities, and $g$ is the gravitational acceleration. The droplet relaxation time scale $\left(\tau_{\mathrm{d}}\right)$ is given as

$$
\tau_{\mathrm{d}}=\frac{\rho_{\mathrm{d}} \mathrm{D}_{\mathrm{d}}^{2}}{18 \mu_{\mathrm{g}}} \frac{1}{1+\mathrm{aRe}}
$$

where $D_{d}$ is the droplet diameter and $R e_{d}$ is the droplet Reynolds number. The above correlation is valid for $R e_{d} \leq 800$. The constants $\mathrm{a}=0.15 ; \mathrm{b}=0.687$ yield the drag within $5 \%$ from the standard drag curve. 


\section{Droplet Evaporation Model}

Energy balance of a droplet under evaporative cooling obeys the following equation [17]:

$$
m_{d} C p_{d} \frac{d T_{d}}{d t}=Q-I L
$$

Left hand side of Eq.(5) shows accumulation of heat in the droplet, the $1^{\text {st }}$ term of right hand side and $2^{\text {nd }}$ term are sensitive heat transferred from surrounding air to the droplet and latent heat deprived from the droplet due to evaporation respectively, the energy balance of surrounding air obeys following equation:

$$
m_{g} C p_{g} \frac{d T_{g}}{d t}=-Q
$$

Assuming the droplet is a spherical shape because typical fogging droplets are fine $(\sim 20 \mu \mathrm{m}), Q$ and the rate of mass transfer due to evaporation $I$ may be expressed by

$$
\begin{gathered}
Q=\pi D_{d} N u \lambda_{g}\left(T_{\infty}-T_{d}\right), \\
I=-\frac{d m_{d}}{d t}=\pi D_{d} S h D_{f} \rho_{g}\left(Y_{d}-Y_{\infty}\right), \\
N u=2+0.552 \operatorname{Re}^{\frac{1}{2}} P r^{\frac{1}{3}} \\
S h=2+0.552 R e^{\frac{1}{2}} S c^{\frac{1}{3}}
\end{gathered}
$$

where $Y$ is mass fraction of steam in humid air and Reynolds number $R e$ in Eqs.(9) and (10) is defined by relative velocity between air and droplet. Transport properties $D_{f}, \rho_{g}, \lambda_{g}$ in humid air were evaluated using $1 / 3$ rule [15] namely

$$
\begin{gathered}
\varphi_{g}=Y_{r} \varphi_{1}\left(T_{r}\right)+\left(1-Y_{r}\right) \varphi_{2}\left(T_{r}\right), \\
T_{r}=T_{d_{s}}+\frac{T_{\infty}-T_{d_{s}}}{3}, \\
Y_{r}=Y_{d_{s}}+\left(Y_{\infty}-Y_{d_{s}}\right) / 3 .
\end{gathered}
$$

where $\varphi$ represents transport property and its suffixes 1 and 2 denote steam and dry air respectively.

Above isolated droplet model could be applied to the evaporation of single size water droplets flowing through gas turbine inlet duct with zero slip velocity. When this phenomenon happens uniformly, each droplet has no interaction to one another and the phenomenon can be described by a single droplet. Then, the mass of the surrounding air $m_{g}$ in Eq. (6) is substituted by the ratio of mass velocity of air divided by the number of droplets discharged per unit time. The operator $\frac{d}{d t}$ in Eqs.(5) and (6) may be replaced by $u \frac{d}{d x}$ in steady state. Let us denote this model 1D model hereafter. The 1D model is no longer applicable where droplet interaction exists e.g. spatial inhomogeneity, existence of slip velocity, distributed droplet size, coalescence and so on.

To deal with this problem of droplet interaction, commercial CFD, ANSYS Fluent ${ }^{\mathbb{R}}$ v.14.5 was used. An Euler-Lagrange dispersed particle model was used to compute the two phase flows. The air is the continuous phase and the water droplet is the dispersed phase. The velocity, turbulence parameters etc. were computed at first in Euler system, and then the traces of water droplets were obtained by integral in Lagrange framework after taking the turbulence diffusion and aerodynamic force from the continuous phase into account. Fluent adopts parcel approximation that treats a group of droplet with the same property instead of individual droplets to save computation resource. Each droplet within the parcel is described using above evaporation model (Eqs.(5) (13)) in which $m_{g}$ is taken as the air mass inside a computational element where the parcel exists.

\section{Geometrical Configuration}

Before modeling a droplet evaporation and coalescence in Lshaped duct, a preliminary validation for a single droplet must be done. A single droplet evaporation model was performed in straight duct as shown in Fig.2 Figure 2 shows the simple rectangular duct geometry with $1 \mathrm{~m} \times 1 \mathrm{~m}$ in cross section and $30 \mathrm{~m}$ in length. Mesh in the plane perpendicular to the air flow direction was generated homogeneously to avoid drift. 400 parcels were injected every time step at all elements at inlet plane with the speed same as inlet air velocity.
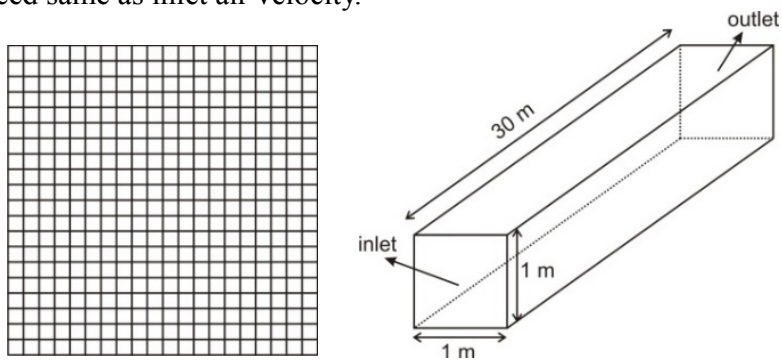

Fig.2 Model domain in simple duct geometry.

\section{Simulation parameters}

As the boundary condition (BC), inlet velocity and pressure outlet were fixed. Temperature initial conditions were set at inlet and outlet. Water droplets were injected as a form of the parcel at inlet surface (surface injection) with specific amount of mass flow rate. The symmetry boundary conditions (reflective $\mathrm{BC}$ ) as well as slip BC were applied to the side walls. The droplets were assumed to rebound elastically once they reach the wall resulting in no loss of water at wall. This assumption was chosen in order to simulate a single droplet at a rest. Therefore, continuous phase and droplets velocity was set at same value in the simulation. In addition, droplets must be still remaining in calculation domain even though encounter the boundary.

In this condition, transient calculation was executed and convergence was judged when the average value of ambient temperature $(\mathrm{Ta})$ and Relative Humidity $(\mathrm{RH})$ at outlet reached steady state condition. Simulations were carried out on Windows 7, Intel ${ }^{\circledR}$ Core $^{\mathrm{TM}}$ i7 $3.40 \mathrm{GHz}$ with RAM memory 8 GB.

\section{Model validation with single size droplet}

The validation is needed in order to confirm the results with experimental data. Ranz and Marshall [7] experimental data for the evaporation of an isolated water drop in an infinite room was used.

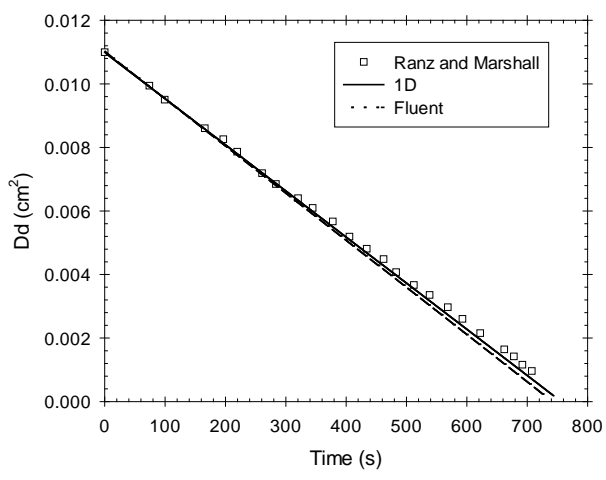


Fig.3 Comparison of droplet diameter with the experimental results by Ranz and Marshall [7].

Experimental condition is with droplet diameter of $0.10488 \mathrm{~cm}$, droplet temperature $(\mathrm{Td})$ of $9.11^{\circ} \mathrm{C}$, ambient temperature (Ta) of $24.9{ }^{\circ} \mathrm{C}$ and ambient pressure of $741 \mathrm{mmHg}$. The experiment was done with a water drop in still dry air. Therefore relative humidity $(\mathrm{RH})$ was set to $0 \% \mathrm{RH}$ in the simulation.

Figure 3 shows the comparison of time history of the diameter change of an isolated droplet in an almost infinite room. Excellent agreement is seen among calculations by 1D model, Fluent and experiment. This implies that the evaporation model as well as the parameter setting of parcel approximation in Fluent is appropriate.

Next, applicability of the Fluent model for droplets floating in an unsaturated air stream with no slip velocity was examined. As there have been no experimental data, Fluent simulation was compared with Chaker's calculation [3] and the 1D model. In this comparison, the initial conditions were atmospheric pressure, $T d=$ $21{ }^{\circ} \mathrm{C}, \mathrm{Ta}=30{ }^{\circ} \mathrm{C}, R H=20 \%$. Initial droplet diameter was $20 \mu \mathrm{m}$ and the amount of water droplet injection rate was determined so that relative humidity becomes $96.4 \%$ under full evaporation. Water droplets are known to quickly take up the velocity of air flow within a few milliseconds from the inlet [4]. Therefore, initial velocities of both air $(u)$ and water droplets $\left(u_{d}\right)$ were set to 15 $\mathrm{m} / \mathrm{s}$.

Figure 4 shows the comparison of Fluent calculation with 1D model and with Chaker [3]. Fluent solution at time $t$ was taken as an average value on the plane perpendicular to the flow direction and located at the distance equal to $u \cdot t$ where $u$ is bulk air velocity. It shows that the results from the Fluent model agree well with both 1D model and Chaker's method. Based on this model thus validated, the simulation to examine coalescence effect with distributed droplets diameter was performed.

\section{Distributed droplet diameter}

According to references from previous publications, spray nozzle injects water droplets with size distribution $[8,9]$. The droplets' size distribution was also investigated experimentally in air intake duct and the results showed a good agreement with Rosin Rammler distribution $[10,11,12]$. Therefore, distributed droplet diameter with Rosin Rammler distribution was adopted. In computation the distribution was discretized by a set of twenty diameters between 0.01 and $35 \mu \mathrm{m}$, and twenty parcels per individual diameter were allocated. Thus $8000(=20 \times 20 \times 20)$ parcels were emitted per a time step from the inlet surface consisting of $20 \times 20$ surface elements. Then evaporation simulation using Fluent was performed in simple duct geometry. Results were compared with those for single size droplet diameter.

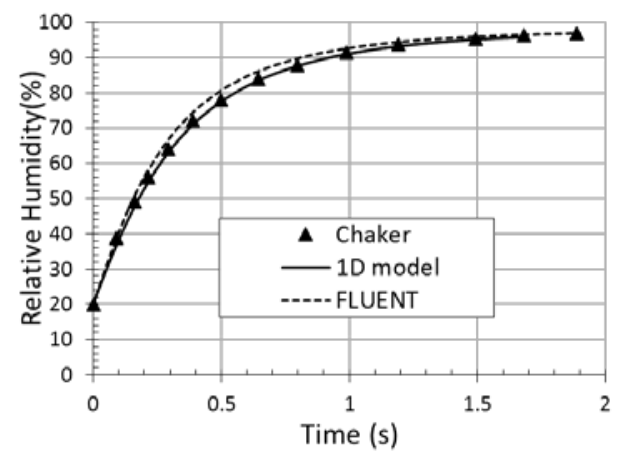

a. Relative Humidity.

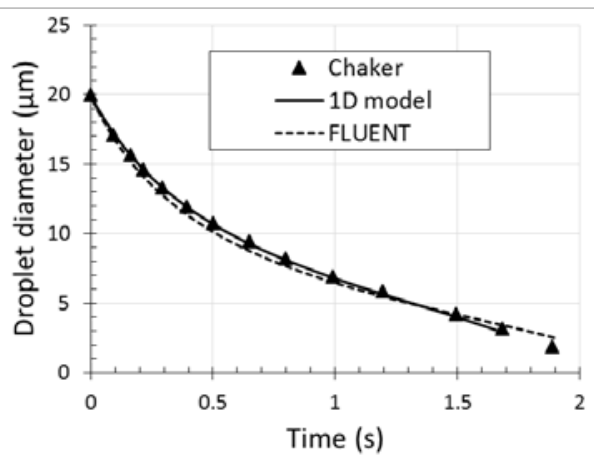

b. Droplet temperature.

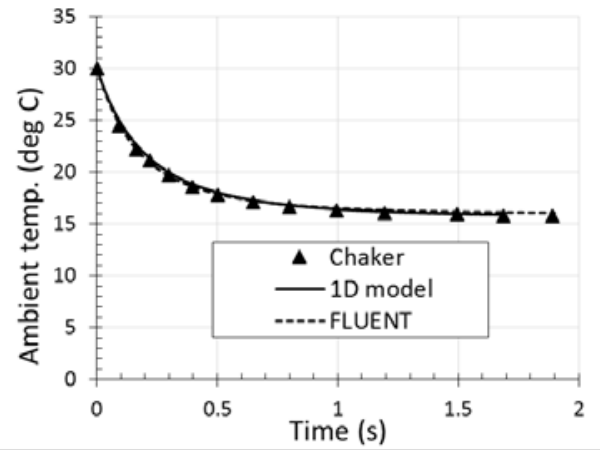

c. Ambient temperature.

Fig. 4 Chaker [3] versus predicted numerical and 1D model method values of relative humidity (a), droplet diameter (b) and ambient temperature (c).

Figure 5 shows generated Rosin Rammler distribution under the condition that Sauter mean diameter (D32) is $8.705 \mu \mathrm{m}$ and D90 is $19.641 \mu \mathrm{m}$. Volume fraction distributions for initial injection profile calculated by Fluent and by 1D model (theory) were compared. Fairly well reproduction has been obtained.

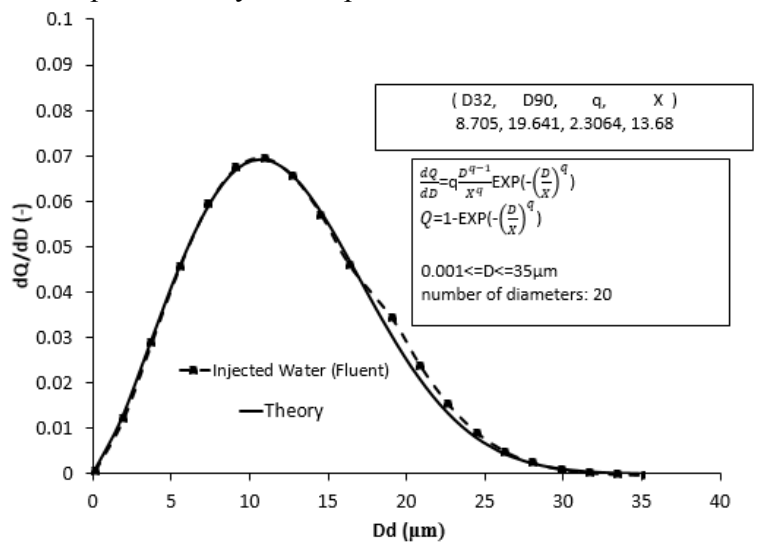

Fig. 5 Comparison of volume fraction distribution with theory.

Figure 6 represents calculated relative humidity values under the same ambient conditions as in Fig. 4. When initial droplet size is single and uniformly $(8.705$ or $20 \mu \mathrm{m})$, it can be seen that droplets completely evaporate for both diameters $8.705 \mu \mathrm{m}$ and $20 \mu \mathrm{m}$ with resultant relative humidity of $96.4 \%$. The former needs 0.3 second and the latter 1.5 second after injection. This is because mass transfer surface area per unit volume increases with lower diameter for sphere, higher rate of evaporation is achieved for smaller droplet. On the contrary, the result of Rosin Rammler distribution does not reach $96.4 \%$ in 1.5 second after injection although enhanced evaporation rate appears during initial stage. This comes from the reduction of evaporation rate possibly caused by following two mechanisms. The first one is the presence of droplets larger than $20 \mu \mathrm{m}$ and the second one is the existence of 
heat transfer interaction among different size droplets through continuous phase. Namely selective evaporation of small droplets at early phase, that causes the surrounding air to cool and reduces heat transfer rate $Q$ in Eq.(5) of large droplets in the neighborhood. This results in lower evaporation rate $I\left(\simeq \frac{Q}{L}\right)$ for the large droplets than in case of no interaction. It has been clarified that under the condition of injected water below saturation amount, analysis using distributed size droplets gives lower evaporation efficiency than the conventional analysis based on single size droplets with diameter of D32. Therefore, it is concluded that the analysis method using D32 as a representative diameter is not conservative in predicting cooling efficiency of inlet fogging under moderate amount of injection rate.

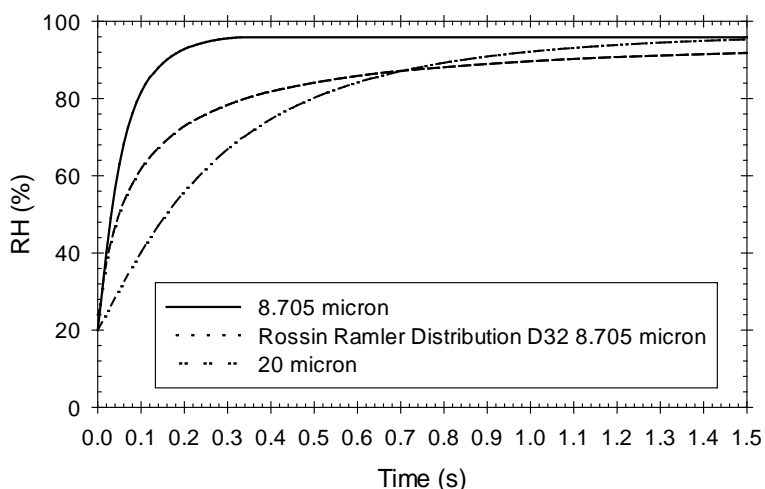

Fig. 6 Relative humidity in the duct-initial conditions: $30^{\circ} \mathrm{C}$ Ta, $21{ }^{\circ} \mathrm{C} \mathrm{Td}, 20 \% \mathrm{RH}$; with droplets of different sizes.

\section{Coalescence model}

Considering size of droplet is small below $40 \mu \mathrm{m}$ of D90 and air velocity is slow $5 \sim 15 \mathrm{~m} / \mathrm{s}$ in inlet duct, the break-up of droplets is not likely to occur. Only the coalescence event was taken into consideration. O'Rourke's algorithm on coalescence is used in Fluent [17]. The algorithm of O'Rourke [13] uses the concept of collision volume to calculate collision probability. Rather than calculating whether or not the position of the smaller droplet center is within the collision volume, the algorithm calculates the probability of the smaller droplet being within the collision volume. It is assumed that the smaller droplet is somewhere within the continuous-phase cell of volume.

Let us consider droplets of parcels present in a specific computational mesh. Assuming parcel droplets with two different diameters denoted by A and B uniformly dispersed, as illustrated in Fig.7 a smaller parcel droplet A may collide with larger parcel droplet $\mathrm{B}$ if $\mathrm{A}$ is located within the cylindrical volume (collision volume) having radius $\sigma_{A B}$ and length $U_{r e l} \times \Delta t$ in which $U_{r e l}$ is relative velocity of parcel droplet $\mathrm{A}$ and $\Delta t$ a time step. As collision probability $P_{1}$ may be expressed by the ratio of the collision volume to the volume of a computational element, $V_{C E L L}$, average number of collisions $\mu$ of a specific smaller droplet with larger parcel droplet with the number $n_{B}$ is

$$
\mu=P_{1} n_{B}=\frac{\pi \sigma_{A B}^{2} U_{r e l} \Delta t}{V_{C E L L}} n_{B} .
$$

Collision probability of the number of actual collisions $\kappa$ obeys Poisson distribution:

$$
P(\kappa)=e^{-\mu} \frac{\mu^{\kappa}}{\kappa !}
$$

The number of collisions between parcels A and B is

$$
N_{A B}=n_{A} \kappa(y) P(\kappa) .
$$

Here $y$ is a random number with uniform distribution between 0 and 1 and $\kappa(0)=\kappa_{\min }, \kappa(1)=\kappa_{\max }$. Whether the collision leads to coalescence is judged as follows: taking the distance between centers of sphere $\mathrm{A}$ and $\mathrm{B}$ on individual collision to be $\mathrm{b}=\left(r_{A}+r_{B}\right) \sqrt{y}$ and if $\mathrm{b}>b_{\text {crit }}$ coalescence is regarded to occur. $b_{\text {crit }}$ is empirically determined :

$$
\begin{gathered}
b_{\text {crit }}=\left(r_{A}+r_{B}\right) \sqrt{\min \left(1, \frac{2.4 f}{W e}\right)}, \\
W e=\frac{\rho U_{r e l}^{2} \sigma_{A B}}{\sigma}, \\
f(R)=R^{3}-2.4 R^{2}+2.7 R, R=r_{A} / r_{B} .
\end{gathered}
$$

As a result of coalescence, a new parcel containing larger droplets $N_{A B}$ is created and the original parcels $\mathrm{A}$ and $\mathrm{B}$ reduce the number of droplets to $n_{A}-N_{A B}$ and $n_{B}-N_{A B}$ respectively. This algorithm is examined by experiment on fuel spray of diesel engines [13, 14].

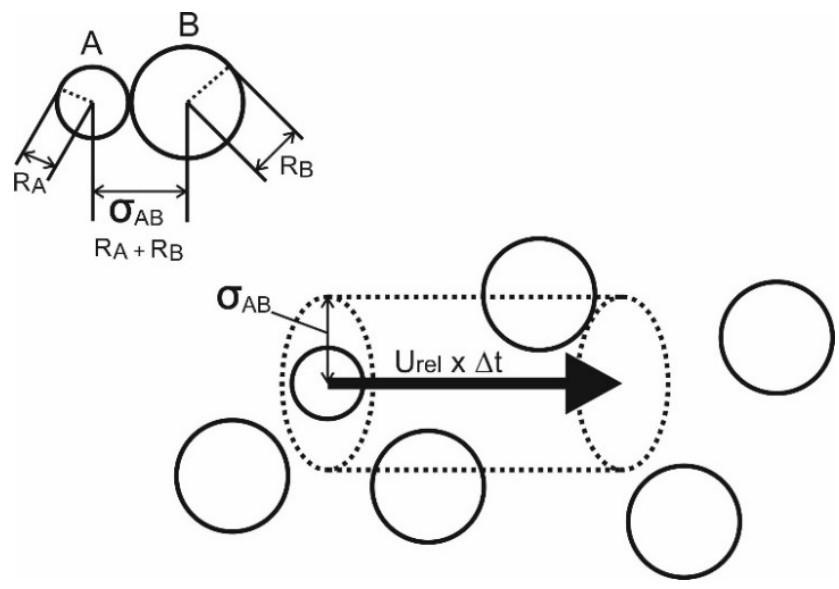

Fig. 7 Concept of collision volume [13].

\section{Coalescence consideration in L-shape duct}

Figure 8 shows the L-shape duct geometry with $1 \mathrm{~m} \times 1 \mathrm{~m}$ in cross section and $30 \mathrm{~m}$ in length in comparison with the actual geometry. As the boundary condition (BC), inlet velocity and pressure outlet were fixed. Temperature initial conditions were set at inlet and outlet. Water droplets were injected in the form of the parcel at inlet surface (surface injection) with specific amount of mass flow rate. The symmetry boundary conditions (reflective $\mathrm{BC}$ ) as well as slip BC were applied to the side walls. In other case, trap $\mathrm{BC}$ was also applied on wall in order to evaluate water drainage. The inlet velocity of air and droplets was set at same value. Moreover, the velocity of droplets was also set 10 times faster than the velocity of air in order to evaluate the coalescence.

This shape geometry introduced the effect of duct geometry on the droplets coalescence phenomenon. In addition, the actual intake duct for inlet fogging is L-shape duct. Inert droplets and non-inert (evaporative) droplets were used to evaluate the droplets coalescence. Instead of using single representative diameter, initial droplets for this simulation had Rosin Rammler distribution with $\mathrm{D} 32=15 \mu \mathrm{m}$ and $\mathrm{D} 90=35 \mu \mathrm{m}$. The operation conditions are $65 \%$ relative humidity $(\mathrm{RH}), 15.85{ }^{\circ} \mathrm{C}$ air temperature $(\mathrm{Ta}), 30^{\circ} \mathrm{C}$ droplet temperature (Td), and water to air mass ratio is $1.63 \%$. The water amount corresponds to such over-fogging condition, that the amount of water required to attain saturation is $0.6 \%$.

As it is known O'Rourke's algorithm depends on density of parcels. To find whether it is insufficient, solutions were compared between time steps of $0.01 \mathrm{~s}$ and $0.001 \mathrm{~s}$, in which the model discharged 10 times more parcels per unit time. It was examined that both results agreed within $1 \%$ difference. Therefore, it was 
judged that there the number of parcels is high enough with time step of $0.01 \mathrm{~s}$ for the algorithm to work in high precision.
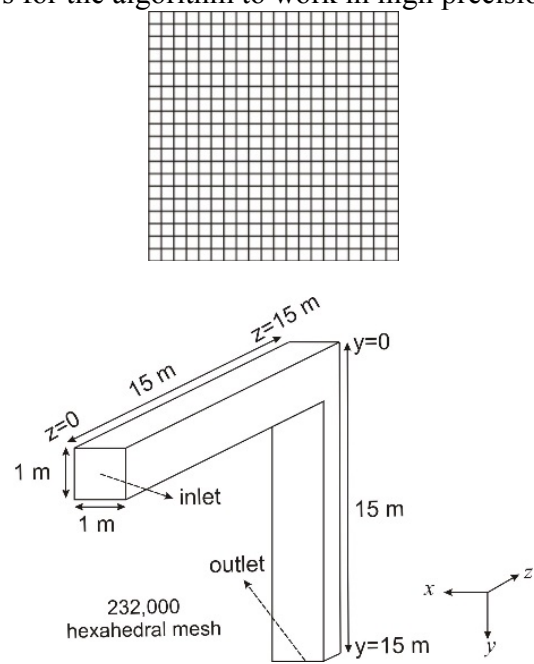

a. Model geometry.

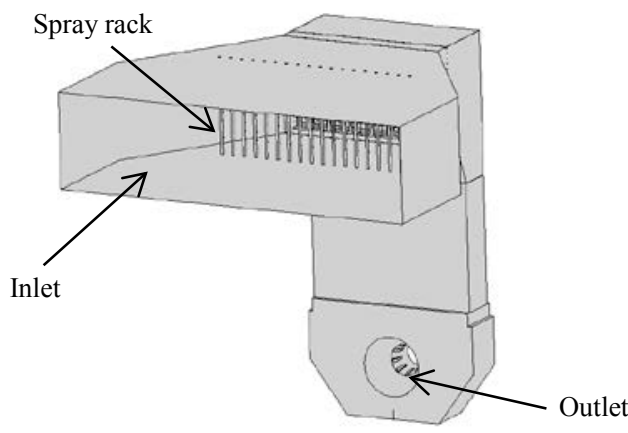

b. Actual intake air duct geometry.

Fig. 8 Model and actual L-shape duct geometry.

\section{RESULTS AND DISCUSSIONS}

\section{Droplets coalescence}

The relative humidity and air temperature of non-inert droplets in every position of $\mathrm{L}$ duct is shown in Fig.9. It can be seen that the condition is saturated within $2 \mathrm{~m}$ from inlet or 0.13 seconds after the injection. Air temperature reduced to $11.839{ }^{\circ} \mathrm{C}$ while wet bulb temperature taken from PROPATH was $11.549^{\circ} \mathrm{C}$ [16]. Both values are very close, which seems reasonable.

Figure 10 compares Sauter mean diameter of droplets (D32) as a function of position between non-inert (evaporative) droplets and inert (non-evaporative) ones. Sudden increase of D32 near inlet and plateau thereafter indicate that smaller diameter non-inert droplets disappear due to quick evaporation while larger droplets receive little coalescence. Droplets with initial D32 $15 \mu \mathrm{m}$ will evaporate because the air stream is under-saturated condition. What is occurring is that the smallest droplets evaporate quicker. As a result of this, the average diameter of the remaining population is increasing. However, D32 remains constant after $\mathrm{z}=$ $2 \mathrm{~m}$ due to the air condition has been saturated.

On the contrary, D32 for inert droplets remain constant before $\mathrm{z}=10 \mathrm{~m}$ or 0.6 second. According to Chaker et al [18], smallest droplets with diameter smaller than 15 micron have a small response time, less than $1 \mathrm{~ms}$. This means that smallest droplets will move faster compared to bigger droplets, in case of the change of velocity of air stream (initial velocity of droplets and air stream are the same). Therefore, the D32 increases after $\mathrm{z}=10 \mathrm{~m}$, where velocity profile of air starts changing influenced by the Lcorner. It is because smaller droplets move faster than larger droplets (see Fig. 11). As a result, smaller droplets will coalesce with neighboring droplets of bigger diameter. Moreover, the number of smaller droplets is much larger for inert case than for evaporative case, this enhances coalescence. To illustrate this correlation between droplet diameter and the number of parcels. Figure 12 shows the number of parcels for each droplet diameter. The number of parcel at initial condition is shown in Fig. 12 a. It can be seen in Fig. 12 a that the number of parcels for each droplet is 400. Furthermore, in Fig. 12 b, there are two cases. Case 1 represents the droplets velocity and air -stream are $15 \mathrm{~m} / \mathrm{s}$ at initial condition. Case 2 represents the droplets velocity is $150 \mathrm{~m} / \mathrm{s}$ and air stream velocity is $15 \mathrm{~m} / \mathrm{s}$ at initial condition (droplets velocity 10 times faster than air-stream velocity). It can be seen in Fig. 12 $b$ that the probability of droplets' coalescence significantly increases the number of parcels in bigger droplet diameter. It can be concluded that coalescence creates bigger droplet and the probability of droplets' coalescence increases when droplets velocity is faster than air-stream velocity at initial condition.

In addition, after $\mathrm{z}=14 \mathrm{~m}$, just before elbow, D32s of both inert and non-inert droplets increase drastically, this may be caused by an onset of coalescence. To confirm this hypothesis droplet volume flow rate distribution and velocity contour were examined as shown in Figs. 13 and 14.

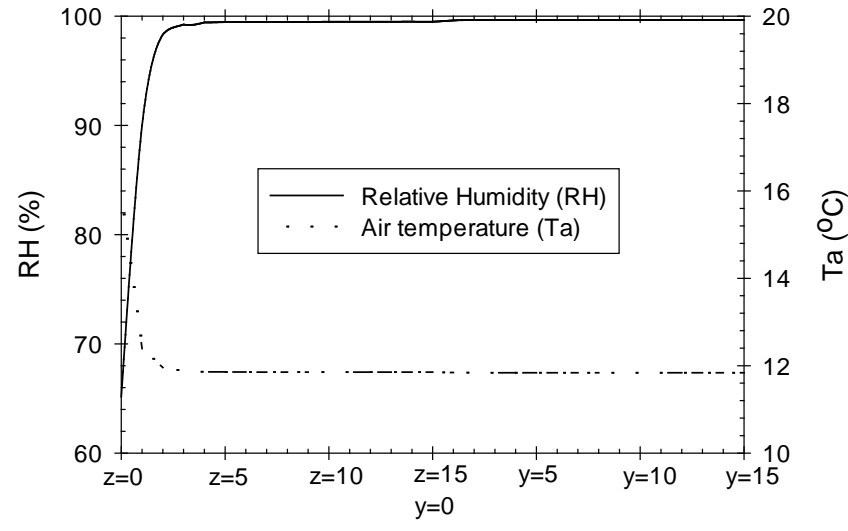

Position in $z$ and y coordinate $(\mathrm{m})$

Fig. 9 Relative humidity (RH) and air temperature (Ta).

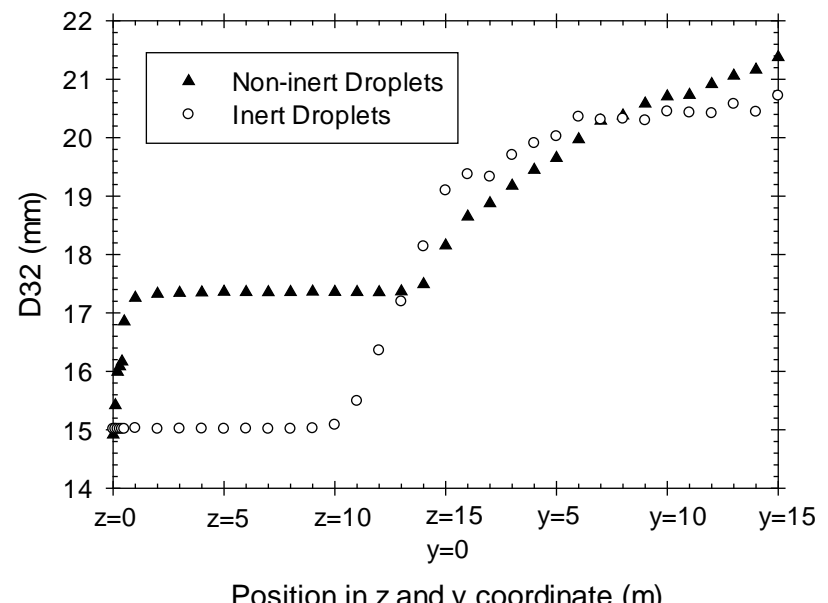

Fig. 10 Sauter mean diameter (D32) in every position. 
$(\mathrm{m} / \mathrm{s})$
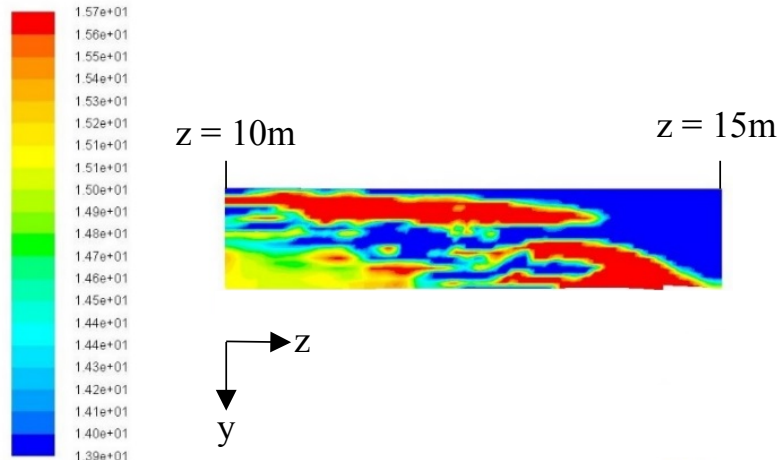

Fig. 11 Instantaneous absolute velocity magnitude of inert droplets at position $\mathrm{z}=10 \mathrm{~m}$ to $\mathrm{z}=15 \mathrm{~m}$.

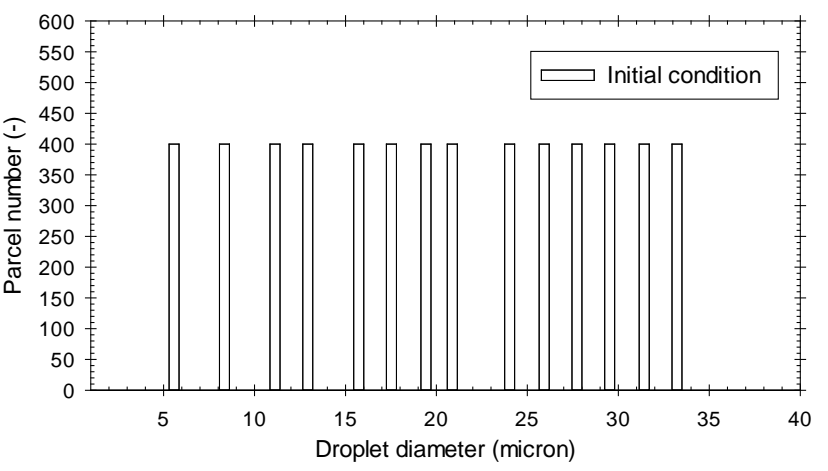

a. Initial condition.

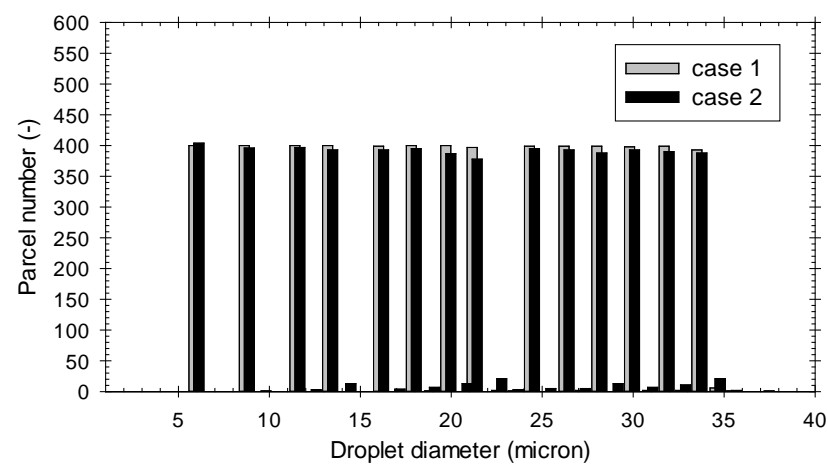

b. Case 1: Droplets velocity $=15 \mathrm{~m} / \mathrm{s}$ and air-stream velocity $=15$ $\mathrm{m} / \mathrm{s}$, Case 2: Droplets velocity $=150 \mathrm{~m} / \mathrm{s}$ and air-stream velocity $=$ $15 \mathrm{~m} / \mathrm{s}$.

Fig. 12 The number of parcels for each droplet diameter.

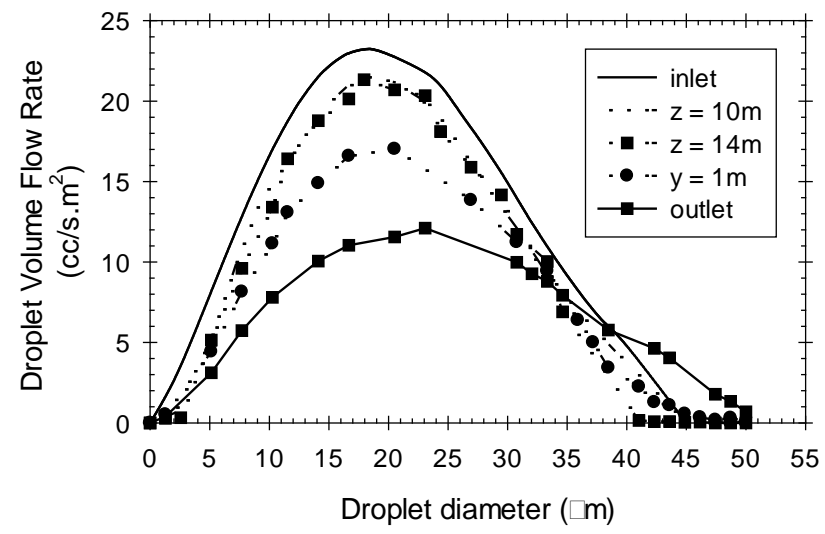

Fig.13 Droplet volume flow rate at different positions.
Figure 13 shows a droplet volume flow rate for non-inert droplets. The initial droplets for this simulation had Rosin Rammler distribution with $\mathrm{D} 32=15 \mu \mathrm{m}$. The operation conditions are $65 \%$ relative humidity $(\mathrm{RH}), 15.85{ }^{\circ} \mathrm{C}$ air temperature $(\mathrm{Ta})$, $30^{\circ} \mathrm{C}$ droplet temperature (Td), and water to air mass ratio is $1.63 \%$. It can be seen in Fig. 13 that the coalescence effect becomes significant from elbow at $\mathrm{y}=0 \mathrm{~m}$ to outlet at $\mathrm{y}=15 \mathrm{~m}$ although the mass of droplets is unchanged after $\mathrm{z}=2 \mathrm{~m}$. The reason is that there is a drift flow around the corner and accelerating and decelerating flow field develops as shown in Fig.14. This increases density of droplets as well as relative velocity $U_{\text {rel }}$ in Eq. (14) and average number of collisions $\mu$. As a result, the number of collisions and volume fraction of larger droplets increase.

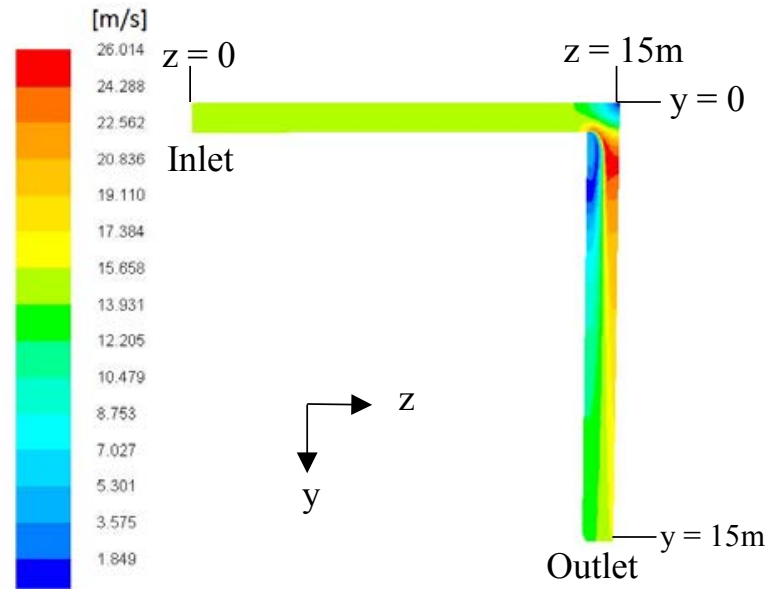

Fig.14 Time-average of air velocity in L-duct cross section ( $\mathrm{z}$ and y cross-sectional).

\section{Influence of duct geometry on cooling efficiency}

Cooling efficiency is defined by the ratio of actual temperature reduction to ideal temperature reduction (=dry bulb-wet bulb). Evaluation of the cooling efficiencies in a straight duct (case1) and L-shape duct (case2) was performed under moderate injection rate with water to air mass ratio of $0.578 \%$. The initial conditions for both geometries are the same as those shown in Fig.6. This condition gives $96.4 \% \mathrm{RH}$ after full evaporation of injected water. Figure 15 shows droplet volume flow rate for case 1 and case 2 . From this figure, it can be seen that the water droplets are not fully evaporated but partly remain as droplets at exit for both cases. Detailed results can be seen in Table 1. The amount of unevaporated water in L-shape duct is bigger than straight duct, which results in worse cooling efficiency in L-shape duct. This indicates that coalescence phenomenon in L-shape duct may deteriorate cooling efficiency even in moderate amount of water injection.

\section{Drainage evaluation}

Non-evaporated water droplets still remain in intake duct, as shown in Table 1. They may increase the water drainage as Lshape duct enhances the coalescence and tends to make larger droplets. To confirm this hypothesis comparative analysis for water drainage was done in $\mathrm{L}$-shape duct between coalescence and non-coalescence models. The operation conditions were $65 \%$ relative humidity $(\mathrm{RH}), 15.85{ }^{\circ} \mathrm{C}$ air temperature $(\mathrm{Ta}), 30^{\circ} \mathrm{C}$ droplet temperature (Td), and water to air mass ratio amount $1.63 \%$. The initial water droplets have a Rosin Rammler distribution with $\mathrm{D} 32=15 \mu \mathrm{m}$. Those conditions are same as those shown in Figs.9 13. 
Table 1 Physical properties comparison.

\begin{tabular}{|c|c|c|c|}
\hline \multicolumn{2}{|c|}{ Properties } & $\begin{array}{c}\text { Straight } \\
\text { duct } \\
\text { (case1) }\end{array}$ & $\begin{array}{c}\text { L duct } \\
\text { (case2) }\end{array}$ \\
\hline \multirow{2}{*}{$\begin{array}{l}\text { Results } \\
\text { (outlet) }\end{array}$} & $\mathrm{Ta}\left({ }^{\circ} \mathrm{C}\right)$ & 16.4613 & 16.6425 \\
\cline { 2 - 4 } & $\mathrm{RH}(\%)$ & 92.9998 & 91.3164 \\
\cline { 2 - 4 } & Non-evaporated water (\%) & 1.787 & 2.165 \\
\cline { 2 - 4 } & Cooling efficiency (\%) & 94.61 & 93.34 \\
\hline
\end{tabular}

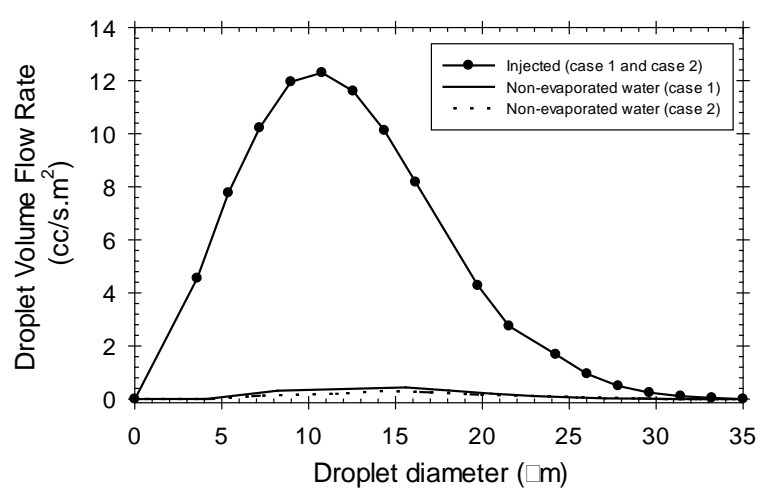

Fig. 15 Droplet volume flow rate in straight duct and L-shape duct.

Boundary condition on the wall was changed to trap BC, in order to evaluate water drainage on the wall (especially after the bent).

The amount of water drainage corresponds to droplets trapped - corner zone in Table 2. It can be seen that the amount of water drainage in coalescence model is bigger than non-coalescence model. This means the amount of water drainage is increasing while including the droplet coalescence.

Table 2 Mass transfer summary.

\begin{tabular}{|l|c|c|}
\hline Fate of droplets & $\begin{array}{c}\text { Coalescence } \\
\text { model }\end{array}$ & $\begin{array}{c}\text { Non-Coalescence } \\
\text { model }\end{array}$ \\
\hline Evaporated & $2.662 \times 10^{-2} \mathrm{~kg}$ & $2.681 \times 10^{-2} \mathrm{~kg}$ \\
\hline Trapped - corner zone & $1.925 \times 10^{-1} \mathrm{~kg}$ & $1.672 \times 10^{-1} \mathrm{~kg}$ \\
\hline Escaped - outlet zone & $3.098 \times 10^{-1} \mathrm{~kg}$ & $3.230 \times 10^{-1} \mathrm{~kg}$ \\
\hline
\end{tabular}

Figure 16 shows Sauter mean diameter on every plane for both coalescence and non-coalescence models with evaporative droplets. Result of coalescence model is same as the non-inert droplets in Fig.10. D32 for both coalescence and non-coalescence are almost the same before $\mathrm{z}=15 \mathrm{~m}$. However, D32 in noncoalescence model is decreasing after $\mathrm{z}=15 \mathrm{~m}$ while almost constant after $y=4 \mathrm{~m}$ after the corner. This means the trap of larger droplets happens mainly between $\mathrm{z}=14 \mathrm{~m}$ and $\mathrm{y}=4 \mathrm{~m}$. On the contrary, D32 in coalescence model is increasing from $\mathrm{z}=$ $15 \mathrm{~m}$ to $\mathrm{y}=15 \mathrm{~m}$. To see what happens, droplet volume flow rate was analyzed in detail.

Figures 17 and 18 show the droplet volume flow rate through planes perpendicular to flow direction both at $\mathrm{y}=1 \mathrm{~m}$ and $\mathrm{y}=10 \mathrm{~m}$ downstream from corner for non-coalescence and coalescence models respectively. It can be seen that the droplet volume flow rates for droplets with larger diameter decrease more in noncoalescence model but increase in coalescence model in the area between $\mathrm{y}=1 \mathrm{~m}$ and $\mathrm{y}=10 \mathrm{~m}$.

Figure 19 shows drainage rate and the rate of net production of secondary droplets as a result of coalescence in the range between $\mathrm{y}=1 \mathrm{~m}$ and $\mathrm{y}=10 \mathrm{~m}$. Negative values indicate disappearance rate of smaller droplets that exist before coalescence exceeds production rate at a specific diameter. Clearly the rate of creation of larger droplets by coalescence exceeds the drainage loss rate in larger diameter zone. That is why D32 increases after L-corner in coalescence model in Fig. 18.

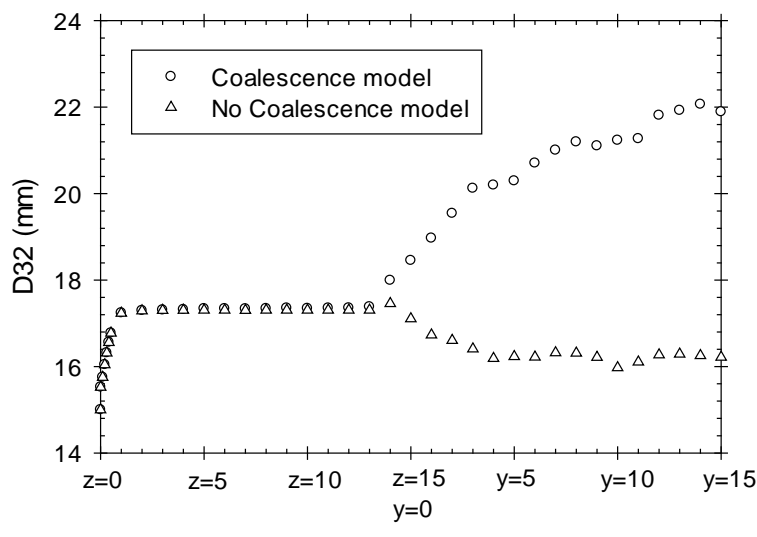

Position in $z$ and $y$ coordinate $(\mathrm{m})$

Fig. 16 Sauter mean diameter (D32) in every position.

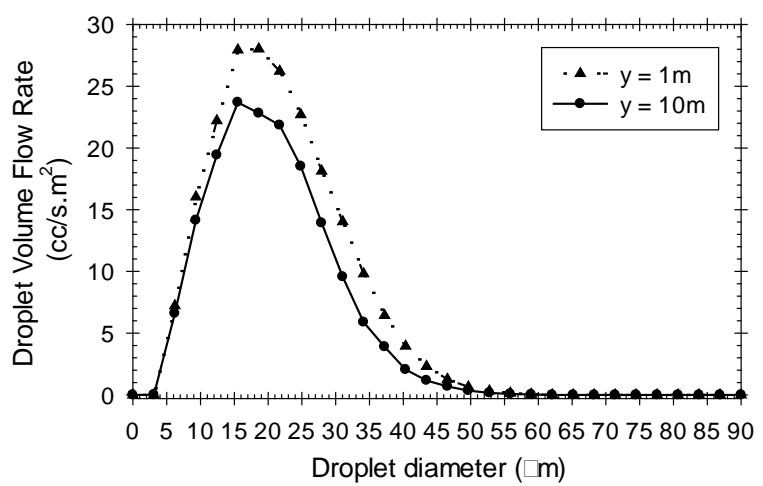

Fig. 17 Droplet volume flow rate for non-coalescence model

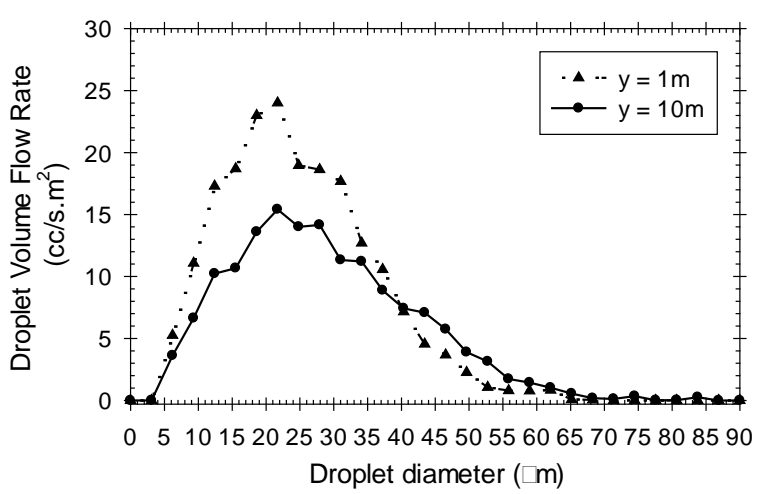

Fig. 18 Droplet volume flow rate for coalescence model.

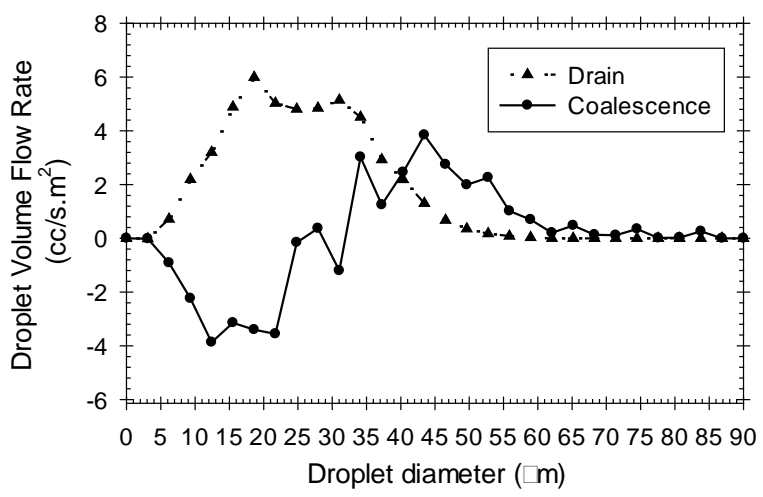

Fig. 19 Volume flow rates for drainage and coalescence in the volume between $16 \mathrm{~m}$ and $25 \mathrm{~m}$ downstream the bent. 


\section{CONCLUSIONS}

Water droplet evaporation behavior in the inlet duct of a gas turbine during inlet fogging operation was numerically investigated using simplified geometry with special emphasis upon multi-disperse droplet characteristics and droplet coalescence event. Rosin Rammler distribution was adopted to characterize multi-disperse droplets. Following results were obtained.

(1) The numerical calculation was executed by ANSYS Fluent ${ }^{\mathbb{R}}$ v.14.5 in a simple rectangular duct and verified with experimental data. The calculated evaporation time of an isolated droplet in an infinite room shows a good agreement with experimental data.

(2) Evaporation efficiency of multi-disperse droplets was lower than that of single-disperse droplets represented by D32 under the condition of unsaturated fogging amount. It is attributed to the interaction among droplets of different size. Smaller droplets evaporate faster and cool the surrounding air much more than the case of single disperse droplets, which retards evaporation rate of larger droplets. Therefore, it is concluded that analysis using single diameter D32 overestimates evaporation efficiency and multi-dispersed approach is needed for higher accuracy.

(3) Coalescence is enhanced in L-shape duct. Due to large velocity gradient around corner, larger droplets are generated. This may cause increased drainage and entrainment of larger droplets into compressor. The coalescence becomes enhanced under over fogging operation. On the contrary, the deterioration of cooling efficiency is anticipated under moderate fogging operation. Hence suppression of coalescence is suggested for an efficient operation of inlet fogging.

So far, O'Rourke's coalescence model adopted here has been verified by the experiment for coalescence event happening inside spray fog. However, further experimental validation focused on Lshape duct is strongly advised for a future work.

\section{ACKNOWLEDGMENTS}

This research was made possible by the financial support of the Ministry of Economy, Trade and Industry of Japan, Agency for Natural Resources and Energy. The authors wish to express their deep gratitude.

\section{REFERENCES}

[1] Han, J. C., Dutta, S., and Ekkad, S., 2012, Gas Turbine Heat Transfer and Cooling Technology. CRC Press.

[2] Utamura, M., Takehara, I., and Karasawa, H., 1998, MAT, a Novel, Open Cycle Gas Turbine for Power Augmentation, Energy Conversion Management, Vol. 39, pp.1631-1642.

[3] Chaker, M., A., Meher-Homji, C. B., \& Mee, T., 2002, Inlet fogging of gas turbine engines Part-A, Fog droplet thermodynamics, heat transfer and practical considerations, GT2002-30562, Proceedings of ASME Turbo Expo.

[4] Chaker, M.A., Meher-Homji, C. B., \& Mee, T., 2002, Inlet fogging of gas turbine engines Part-C, Fog behavior in inlet ducts, CFD analysis and wind tunnel experiments, GT200230564, Proceedings of ASME Turbo Expo.

[5] Jeanty, F., De Andrade, J., Croquer, S., Correa, J. L. C., \& Asuaje, M., 2012, Numerical Analysis of a Fogging System in a Gas Turbine. In ASME Turbo Expo 2012: Turbine Technical Conference and Exposition (pp. 913-923). American Society of Mechanical Engineers.

[6] Suryan, A., Kim, D. S., \& Kim, H. D., 2010, Experimental study on the inlet fogging system using two-fluid nozzles. Journal of Thermal Science, 19(2), 132-135.

[7] Ranz, W. E. and Marshall, W. R. Jr., 1952 ,Evaporation from Drops, Part II, Chemical Engineering Progress, Vol.48, pp.
173-180.

[8] Chaker, M.A., Meher-Homji, C. B., \& Mee, T., 2002, Inlet Fogging of Gas Turbine Engines: Part B-Fog Droplet Sizing Analysis, Nozzle Types, Measurement and Testing. In ASME Turbo Expo 2002: Power for Land, Sea, and Air, pp. 429-441, American Society of Mechanical Engineers.

[9] Chaker, M. A., Meher-Homji, C. B., \& Mee, T., 2003, Inlet Fogging of Gas Turbine Engines: Experimental and Analytical Investigations on Impaction Pin Fog Nozzle Behavior, ASME Turbo Expo 2003, collocated with the 2003 International Joint Power Generation Conference, pp. 863879.

[10] Semião, V., Andrade, P., and Carvalho, M. D. G., 1996, Spray Characterization: Numerical Prediction of Sauter Mean Diameter and Droplet Size Distribution, Fuel, Vol. 75, no. 15, pp.1707-1714.

[11] Lefebvre, A. H., Atomization and sprays, Hemisphere Publishing Corporation, 1989.

[12] Shibata, T., Myoren, C. and Hatamiya, S., 2004, Evaporative behavior of multi-dispersed droplets flowing through gas turbine inlet duct (in Japanese), Proc. Power reactor and Energy Symposium.

[13] O'Rourke, P, J., 1981, Collective Drop Effects on Vaporizing Liquid Sprays, Ph.D. Dissertation, Princeton University.

[14] Hiroyasu,H. and Kadota, T.,1974, Fuel droplet size distribution in diesel combustion chamber, $S A E$ paper 740715.

[15] Hubbard, G.L., Denny, V.E., Mills, A.F., 1975, Droplet evaporation: Effects of transients and variables properties, Int. J. Heat Mass Transfer, 18, pp1003-1008.

[16] PROPATH group, 1990, PROPATH: a program package for thermo-physical properties of fluids, ver. 10.2, Corona Publishing Co., Tokyo, Japan.

[17] FLUENT Theory Guide, Release 14.5.7, 2012, ANSYS Inc.

[18] Chaker, Mustapha, Cyrus B. Meher-Homji, and Thomas Mee. 2004, Inlet fogging of gas turbine engines-Part III: Fog behavior in inlet ducts, computational fluid dynamics analysis, and wind tunnel experiments, Journal of engineering for gas turbines and power 126.3: 571-580. 